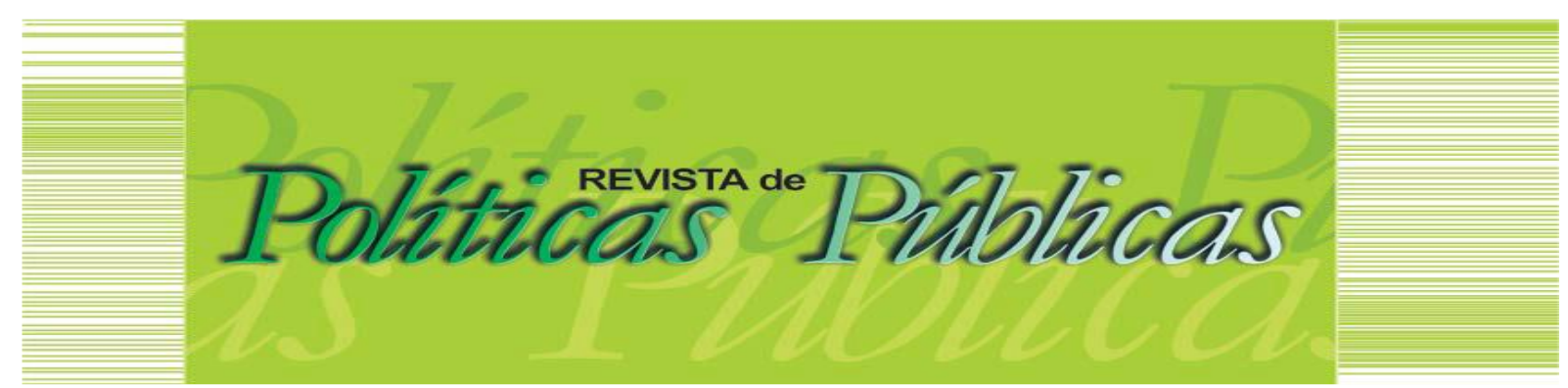

\title{
CONSELHOS EM “QUARENTENA”? Participação e controle social na política urbana na pandemia da Covid-19
}

\author{
Liana Silvia de Viveiros e Oliveira ${ }^{1}$ \\ Aparecida Netto Teixeira ${ }^{2}$ \\ Maria Auxiliadora da Silva Lobão ${ }^{3}$ \\ Camila Martins de Abreu Farias ${ }^{4}$
}

\section{Resumo}

A pandemia da Covid-19 desnudou a face cruel da política urbana no Brasil, revelada na incapacidade histórica de enfrentar os graves problemas estruturais das cidades. Com uma robusta base jurídica e institucional, essa política pública incorporou instâncias de participação e controle social nos três níveisdo governo, atualmente em processo de desmonte na esfera federal. Num contexto de crise política e sanitária, este artigo, com base em pesquisa documental e bibliográfica, revisita 0 histórico de constituição e atuação do Conselho Estadual das Cidades da Bahia e do Conselho Municipal de Salvador e avalia a atenção dada à pandemia. Os resultados evidenciam as contradições e fragilidades na atuação e a ausência de compreensão, nos âmbitos dos conselhos e dos governos, do potencial dessas instâncias e do indispensável acionamento da política urbana no enfrentamento da pandemia.

Palavras-chave: Covid-19. Pandemia. Conselhos. Política urbana. Salvador. Bahia.

\section{"QUARANTINED" COUNCILS? Participation and social control in urban politics during the Covid-19 pandemic}

\begin{abstract}
The Covid-19 pandemic uncovered a cruel face of urban politics in Brazil, revealed in the historical inability to face the serious structural problems of the cities. Within a sturdy legal and institutional basis, this public policy has incorporated instances of participation and social control at the three government spheres, currently in the process of dismantling at the federal sphere. In a context of political and health crisis, this article revisits the history of the constitution and action of the State Council for the Cities of Bahia and the Municipal Council of Salvador and assesses the support provided to the pandemic, based on documentary and bibliographic research. The results show contradiction and weaknesses in the performance of councils and government scopes, lack of understanding of the potentiality of these instances and the indispensable acting of urban policies when facing the pandemic.
\end{abstract}

Keywords: Covid-19. Pandemic. Councils. Urban Politics. Salvador. Bahia

Artigo recebido em: 21/12/2020 Aprovado em: 20/05/2021

DOI: http://dx.doi.org/10.18764/2178-2865.v25n1p83-103

\footnotetext{
1 Arquiteta e Urbanista. Doutora em Arquitetura e Urbanismo pela Universidade Federal da Bahia (UFBA). Professora Colaboradora do Programa de Pós-Graduação em Território, Ambiente e Sociedade (PPG-TAS) da Universidade Católica do Salvador (UCSAL). E-mail: lianaviveiros9@gmail.com

${ }^{2}$ Arquiteta e Urbanista. Doutora em Estruturas Ambientais Urbanas pela Faculdade de Arquitetura da Universidade de São Paulo (FAUUSP). Professora do Curso de Arquitetura e Urbanismo e Professora Colaboradora do Programa de PósGraduação em Território Ambiente e Sociedade (PPG TAS) da Universidade Católica de Salvador (UCSAL). Email: aparecida.teixeira@ucsal;br

${ }^{3}$ Socióloga, graduada pela FFCH/UFBA.Mestranda do Programa de Pós Graduação em Planejamento Territorial e Desenvolvimento Social (PPGPTDS) da Universidade Católica do Salvador - UCSAL E-mail:maria.lobao@ucsal.edu.br

${ }^{4}$ Arquiteta e Urbanista. Especialista em Planejamento Urbano e Gestão de Cidades pela Universidade Salvador (UNIFACS). Mestranda em Planejamento Territorial e Desenvolvimento Social pela Universidade Católica do Salvador (UCSAL).E-mail: camila.farias@ucsal.edu.br
} 


\section{INTRODUÇÃO}

Os Conselhos de políticas públicas são instâncias colegiadas com relevante papel na formulação das políticas públicas no Brasil, no contexto da redemocratização, por ocasião da promulgação da Constituição Federal cidadã e municipalista de 1988. Conforme exposto por Avritzer (2009), Gohn (2003) e Dagnino (2002) esse processo ensejou a formação de uma ampla e variada institucionalidade participativa, resultando na construção de espaços públicos compartilhados, preconizados por instituições híbridas (AVRITZER, 2005; GAUDIN E PEREIRA, 2005).

Em seus termos está relacionado a um determinado projeto político entendido, conforme Dagnino (2004, p. 98), como o conjunto de interesses, crenças e representações "que orientam a ação política dos diferentes sujeitos" e, consequentemente, a determinados sentidos relativamente às noções de sociedade civil, participação e cidadania, os quais sofrem deslocamentos e inflexões, a depender do projeto político hegemônico em questão.

Tais conselhos, conforme exposto por Tatagiba (2020); Teixeira (2005) representam a terceira fase da implantação de colegiados no Brasil, sendo instituídos por leis específicas, de caráter consultivo ou deliberativo. Ainda segundo Tatagiba (2020, p. 30) "os conselhos apresentam-se como peças centrais no processo de reestruturação das políticas, legitimados pelos novos princípios constitucionais da participação e da descentralização político-administrativa".

Ao longo desses anos, diversas são as experiências acumuladas acerca da atuação dos conselhos, inicialmente nas áreas de saúde e assistência social, posteriormente ampliada para as áreas de política urbana, direitos humanos, segurança alimentar, cultura e outras. Os conselhos de políticas públicas trouxeram como aspecto inovador o rompimento com as políticas clientelistas vigentes até então, quer seja em relação a sua composição paritária (estado e sociedade civil); a eleição dos seus integrantes, mediante instâncias próprias de deliberação, bem como a publicização das discussões e decisões.

Além disso, transformaram-se em instâncias de discussão e pactuação de conflitos, considerando-se a diversidade de interesses em pauta. Um aspecto importante refere-se à atribuição de capacidade decisória dos Conselhos, no tocante à formulação das políticas públicas, o que, entretanto, não avançou em todas as experiências brasileiras.

Toda essa experiência acumulada resultou na produção científica e reflexões críticas acerca dos limites e desafios referentes a atuação dos mesmos (PONTUAL, 2008; TATAGIBA, 2002; ALMEIDA, C; TATAGIBA, 2012). Destes pode-se inferir que, apesar dos problemas e limitações, principalmente no tocante ao caráter deliberativo e à efetiva participação deste órgão colegiado na 
definição e pactuação de políticas públicas, seguem como espaços importantes, sobretudo de articulação e trocas entre movimentos sociais, entidades e outros agentes da sociedade civil. Como destacado por Bobbio (2000), o poder decisório está em inúmeros espaços onde se tomam decisões coletivas. Alargar a democracia participativa significa ampliar essas sedes onde as decisões coletivas sejam tomadas e sejam capazes de influenciar no todo, a ponto de produzir transformações baseadas na justiça social.

Quanto aos conselhos de política urbana, de interesse especial no presente artigo, podese destacar o Conselho Nacional das Cidades (ConCidades)1', criado em 2003, composto por ampla representação, com integrantes dos três níveis de governo e de representantes da sociedade civil. A sua criação, bem como dos Conselhos Estaduais e Municipais está fundamentada no Estatuto da Cidade (10.257/2001) e na luta por direitos e maior controle social de processos e projetos urbanos que têm na cidade o espaço de sua realização, fundamentados na função social da propriedade e da cidade, na gestão democrática das cidades e no acesso à cidadania, pilares do direito à cidade, tal como esboçado na legislação brasileira.

A atuação do ConCidades foi de extrema relevância na formulação das políticas urbanas em âmbito federal2. Entretanto, apesar dos avanços, no campo dos conflitos e disputas o Conselho não conseguiu a aprovação do Sistema Nacional de Desenvolvimento Urbano (SNDU), bem como ficou à margem do processo de discussão e implantação de importantes programas do governo federal, a exemplo do Programa de Aceleração do Crescimento (PAC); Programa Minha Casa Minha Vida. Cumpriu o seu papel na institucionalidade nos limites permitidos pela correlação de forças, até ser extinto no atual governo.

O entendimento sobre como os Conselhos de política urbana se posicionam para fazer avançar a agenda urbana no sentido do seu fortalecimento no período mais recente nos parece necessário, em face da desconstrução dessa política na esfera federal. Com limitações, os conselhos se colocaram na base de experimentação de inúmeros planos, projetos e ações para as cidades e ganharam legitimidade que os credencia no importante papel de tensionar para 0 alargamento da democracia no Brasil. Embora desmobilizados e desprestigiados em muitos contextos, esses órgãos ainda representam brechas na institucionalidade, importantes no contexto atual de afronta à democracia.

$\mathrm{Na}$ atual conjuntura política brasileira, na contramão de todo o processo democrático que vinha sendo implementado, registra-se o processo de desmonte das instâncias participativas, em âmbito federal, com a edição de decretos extinguindo conselhos de políticas públicas no Brasil. Diante do retrocesso político e antidemocrático, o olhar para os conselhos estaduais e municipais em atividade 
pode dar pistas sobre mecanismos de sustentação, mesmo frágeis, da democracia participativa no país.

O contexto atual de crise política e sanitária nos parece ser um bom momento para revisitar essas instâncias, considerando-se a potência dessa crise para promover inflexões, reconduções e transformações. De acordo com Lawrence Grossberg (2015) toda conjuntura está diretamente associada a uma crise orgânica que abrange as diversas dimensões da formação social (política, econômica, cultural, social etc.), sendo uma "realidade historicamente emergente" que demanda uma reflexão da sociedade sobre si mesma, bem como daquilo que ela pode vir a se tornar enquanto atravessa a crise. Representa, portanto, um potencial de conhecimento e de transformação, em si indissociáveis.

No Estado da Bahia, o primeiro caso de COVID-19 foi registrado no município de Feira de Santana-BA, em março de 2020, dando início ao processo de acompanhamento e controle da pandemia que se expandiu rapidamente no Estado. Conforme informações do grupo interdisciplinar e interinstitucional Geocombate Covid 19/BA (GEOCOMBATE, 2020), os 417 municípios baianos apresentam respostas diferenciadas no enfrentamento dos problemas, o que abrange os graus de vulnerabilidades dos municípios, de desenvolvimento econômico local, percepção da população sobre a importância do isolamento social, características da população (faixa etária, etnia, morbidades etc.), até a infraestrutura de saúde disponível para suporte e atendimento em seus diversos níveis. (GEOCOMBATE, 2020, p. 1).

Em Salvador, a Covid-19 veio escancarar a situação de desigualdade social e precariedade habitacional e sanitária característica da metrópole. Registra-se que $20 \%$ do território municipal constitui-se de áreas precárias caracterizadas como ZEIS - Zonas especiais de interesse social,totalizando 234 áreas,que concentram $56 \%$ da população, com elevada densidade populacional e de domicílios, com média de 24.000 hab./ha.(PEREIRA et. al., 2020).

Grande parte dessa população vive em condições precárias de habitabilidade, caracterizadas principalmente pela deficiência no abastecimento de água e esgotamento sanitário, bem como elevada densidade, com a coabitação familiar. Segundo as análises preliminares do Núcleo Salvador do INCT/Observatório das Metrópoles (PEREIRA et. al., 2020) o "planejamento urbano não foi requisitado e nem tampouco oferecido como possibilidade de reforço às estratégias de gestão da crise sanitária da COVID-19". Paralelamente, "as iniciativas da população de autogestão foi o que se apresentou como inovação de aparente eficácia: a mediação das demandas ante as emergências de saúde pela própria comunidade, estabelecendo microterritórios de supervisão e de assistência social"(CORSO et. al, p. 5/15). 
O presente artigo, além de recuperar em perspectiva crítica o histórico de constituição e atuação do Conselho Estadual das Cidades da Bahia e do Conselho Municipal de Salvador, expondo as contradições envolvidas na relação entre sociedade civil e estado, propõe discutir o tratamento dado por esses órgãos à política urbana contexto da pandemia do coronavírus. A metodologia utilizada consiste em pesquisa documental e bibliográfica exploratória a partir da sistematização e análise crítica das atas do ConCidades-BA e do Conselho Municipal de Salvador, do início das suas respectivas atividades até 0 ano de 2020, no curso da pandemia.

Parte-se da hipótese do apagamento desses órgãos colegiados durante a pandemia em duas perspectivas. Por um lado, da falta de importância atribuída ao mesmo, pelo Estado, nesse período crítico, evidenciada na reduzida mobilização e convocação de reuniões, bem como do não reconhecimento do potencial de articulação e trabalho coletivo a partir das redes constituídas pelos agentes em seus respectivos contextos.

Por outro lado, dos próprios Conselhos e seus membros que não utilizaram a prerrogativa legal de autoconvocação e capacidade de pressão para fazer avançar, na crise, a agenda da política urbana, tendo em conta a estreita relação da disseminação da doença com as desigualdades e vulnerabilidades socioespaciais e também dos mecanismos de contenção da doença com essa política pública.

O artigo está estruturado em três tópicos. $O$ primeiro aborda a leitura dos conselhos de política urbana no Brasil no atual contexto de desconstrução da política urbana no Brasil. O segundo trata da conformação de uma agenda de política urbana na pandemia da Covid-19. O terceiro trata do Conselho Estadual das Cidades da Bahia e do Conselho Municipal de Salvador, analisando as respectivas formações, trajetórias e perfis e o envolvimento no combate à pandemia da Covid-19.

2 CONSELHOS DE POLÍTICA URBANA NO BRASIL: uma leitura no contexto de desconstrução da política urbana brasileira

Os avanços e conquistas relativos à construção de uma política urbana participativa ao longo dos últimos quinze anos, a qual tem como um dos instrumentos principais os conselhos de políticas, vêm sofrendo flagrante retrocesso na atual conjuntura política brasileira, no contexto do projeto neoliberal que vem sendo implementado no país desde a década de 1990, fundamentado na privatização e competitividade, com iniciativas como a desregulamentação das legislações trabalhista e previdenciária e a redução de participação do Estado nas questões sociais (BEHRING, 2003; BORÓN, 1995; HARVEY, 2008; SÁDER; GENTILI,1995). 
Conforme afirma Ribeiro (2020, p. 372), esse processo inscreve uma profunda ambiguidade, caracterizada, por um lado, pela "democracia participativa, justiça distributiva, regulação das forças de mercado", e a implantação de uma política urbana progressista, e, por outro, de programas fundamentados no planejamento estratégico e empreendedorismo urbano. Na atualidade, novas questões e desafios são postos no contexto da inflexão ultraliberal e do capitalismo financeirizado (CHESNAIS, 2020; DOWBOR, 2020; RIBEIRO, 2020), com graves ameaças ao direito à cidade (LEFEBVRE, 1991). Segundo Ribeiro (2020, p. 374), estamos vivendo "um momento [...] de desregulação acelerada, voltada para a desarticulação dos sistemas de proteção existentes e para liberação das forças de mercado das amarras institucionais contingentes".

Com as mudanças na correlação de forças e a ascensão das forças políticas conservadoras ao poder central, em 2019, tem início o deliberado processo de desmonte da política urbana brasileira com significativas mudanças nos marcos legais e constitucionais (RIBEIRO, 2020; LIMA; VIVEIROS, 2020). Nesse contexto, registra-se a flagrante afronta aos princípios da reforma urbana e a transformação da política urbana em um verdadeiro campo de disputa, tensionada entre 0 direito à cidade e o urbanismo corporativo (FERNANDES, 2013), no âmbito do capitalismo financeirizado.

Essas questões estão associadas muito fortemente, ao que Dagnino (2004) chamou de deslocamento de sentidos das noções de sociedade civil, participação e cidadania, resultando em um campo de disputa semântica que se revela enquanto disputa entre projetos políticos distintos. Segundo Dagnino (2004, p. 108),esses deslocamentos implicam nadespolitização dessas três noções que redefinem as noções de política e de democracia advindas das lutas pela democratização.

No âmbito da política urbana, conforme exposto em Viveiros; Lima; Souza (2020) a disputa vem sendo pautada na "política urbana corporativa", em flagrante retrocesso político, que vem se materializando em um amplo marco legal.De interesse especial no presente artigo, registra-se o processo de desconstituição, fragilização e desmantelamento dos Conselhos de Políticas Públicas, mediante os Decretos 9076/2017 e Decreto n. 9.759/2019.

O primeiro trata do Conselho Nacional das Cidades, e altera o intervalo de realização da Conferência Nacional das Cidades de três para quatro anos e transfere a competência para convocação da conferência do Concidades, para o Ministério das Cidades, o qual, por sua vez, foi extinto pela Lei $n^{0} 13.844$, de 18 de junho de 2019 , que estabelece as alterações na organização dos órgãos da Presidência da República e dos Ministérios, tendo suas atribuições transferidas para 0 Ministério Desenvolvimento Regional.

O segundo decreto, de caráter mais ampliado, trata da extinção ou limitação dos órgãos colegiados de participação social voltados para a formulação e controle social das políticas públicas, 
nos quais se inclui o Conselho das Cidades ${ }^{3}$. Posteriormente, o Supremo Tribunal Federal (STF) concedeu liminar para suspensão parcial do Decreto 9.759/2019, a partir do entendimento de que o mesmo não poderia ser extinto mediante decreto, já que os conselhos foram criados por lei. Conforme exposto em Viveiros; Lima (2020, p.213) a "extinção dos meios de participação e controle social e introdução de mecanismos de repressão e censura acionados envolvem todas essas expressões da política urbana corporativa em brumas de obscurantismo, cada vez mais densas".Essas medidas em âmbito federal tendem a desmobilizar e enfraquecer as instâncias de participação social em âmbito estadual e municipal. Como sintetizado por Santos Junior, Diniz e Saule Júnior (2020).

\footnotetext{
Nesse cenário, os avanços decorrentes da adoção dos princípios da reforma urbana e do direito à cidade, que foram conquistados através das lutas das classes populares e das políticas institucionais progressistas ao longo dos últimos anos, correm um enorme risco de serem desmontados pela adoção de um modelo de gestão autoritário e opaco às demandas da sociedade, e afinado com o pensamento neoliberal.
}

Vale registrar que apesar do direcionamento político do governo federal para o desmonte das políticas públicas, os estados e municípios ainda detêm a responsabilidade pelos respectivos sistemas de planejamento e de gestão democrática das cidades, conforme preconizado pelo Estatuto da Cidade. $O$ desgoverno verificado no âmbito federal pode encontrar peias que preservem conquistas logradas no contexto em que a política urbana, com limites e pressões próprios aos processos de construção de hegemonia (WILLIAMS, 1979) conseguiu avançar em uma perspectiva de um projeto democrático e participativo no Brasil.

\section{A CONFORMAÇÃO DE UMA AGENDA DE POLÍTICA URBANA NA PANDEMIA DA COVID-19}

Em contexto de pandemia, à primeira vista não parece razoável pensar em políticas de longo prazo e estruturantes, quando esforços e recursos públicos são mobilizados e direcionados para uma pauta de emergência de saúde pública de importância internacional relacionada à Covid-19, em vigência de estado decalamidade pública, conforme estabelecido pelo Decreto Legislativo no 6 de 2020, e seguido nos estados e municípios do Brasil.

Na pandemia da Covid-19, pelo menos três vertentes de ação estatal, encaminhadas no país, guardam relação direta com a política urbana: uma voltada para a contenção da disseminação da doença, de caráter preventivo e protetivo, com destaque para o comando do distanciamento social; outra para a criação das condições de tratamento da doença, como a construção de hospitais de campanha, unidades de isolamento e outras e, uma terceira, também importante, para ampliar a oferta de vagas em cemitérios. Uma agenda ampla, nos três níveis de governo, se apresenta na complexa e 
intrincada rede de conexões necessárias, requerendo atuação interfederativa e intersetorial, inclusive e fortemente entre política de saúde e política urbana.

Não há dúvidas que o enfrentamento à pandemia convoca a política urbana em muitos aspectos, mesmo do modo paradoxal de restrição temporária ao exercício do direito à cidade, como 0 direito ao espaço público, à centralidade, ao encontro e à festa, como entendido por Lefebvre (1991). Podemos dizer que a política urbana, em tempos de pandemia, é requerida no seu negativo ou no seu avesso, mas nem por isso deixa de se conformar como política urbana. Fechamento de fronteiras, bloqueio de vias, alterações no funcionamento do sistema de transportes, fechamento de praças, proibição do uso de praias, lockdown, criação de ciclovias, dentre outras, configuram a indispensável política urbana da/na pandemia, com seu caráter temporário e emergencial. Cria uma agenda que coloca o espaço público sob restrições, reconfigura a operação de serviços urbanos e realiza intervenções nos espaços da cidade e assim altera a dinâmica da vida coletiva nas cidades.

Ativa e realça, por outro lado, a política urbana na sua face cruel de não ter sido orientada historicamente no Brasil, para enfrentar os grandes e graves problemas estruturais das cidades. Essa face se expõe na expansão e maior letalidade da doença nos territórios populares e coloca em relevo a importância e urgência no desenvolvimento de ações emergenciais e de políticas habitacionais estruturantes e continuadas. Entretanto, a sua urgência,ao que se infere, não tem sido suficiente para colocar o tema na agenda pública.

De fato, o comando do distanciamento social, fundamental no controle da expansão da doença, se defronta com a impossibilidade de grande parte da população atender a essa medida. Em pesquisa realizada pelo Instituto de Saúde Coletiva da Universidade Federal da Bahia (ISC, 2020) para apurar a relação entre distanciamento social e vulnerabilidades em Salvador, os Índices de Isolamento Social (IISs) mais baixos foram registrados nos bairros onde reside a população pobre da cidade, concentrada no Subúrbio Ferroviário e no chamado "Miolo".

Dentre os fatores explicativos dos baixos IISs encontrados nos bairros populares de Salvador, são destacados a ocupação das pessoas de baixa renda em serviços essenciais e atividades informais, que impõe o deslocamento para o trabalho; a falta de qualidade das habitações; maior exposição a problemas financeiros, de saúdee psicológicos, associados ao próprio isolamento social, e a confiança na medida, relacionada à maneira como os governantes atribuem importância à medida e a comunicam na esfera pública.

No contexto de emergência de saúde pública na Bahia e em Salvador foram adotadas diversas medidas para conter a expansão da Covid-19. Apesar das divergências políticas, os gestores públicos conseguiram realizar uma ação coordenada no combate à pandemia nos termos das recomendações da Organização Mundial de Saúde (OMS). Diferentemente da postura negacionista e 
omissa do governo federal (CAPONI, 2020; VANNUCHI, 2020), o governo do estado da Bahia e a Prefeitura Municipal de Salvador conseguiram, com acertos e erros, evitar situações mais críticas de sobrecarga do sistema público de saúde.

Divergências trazidas na dimensão pública ocorreram em situações específicas na esfera dos debates sobre competência e autonomia no encaminhamento das medidas e, nessa seara, "farpas" foram eventualmente lançadas no velho jogo da "transferência" de responsabilidades diante de eventuais ônus políticos, como verificado em matérias de jornais de grande circulação. Em termos gerais conseguiram situar o problema e os encaminhamentos das medidas na esfera da política de saúde em atendimento aos protocolos da OMS.

As políticas de combate à pandemia adotadaspelos governos estadual e municipal no enfrentamento da pandemia, em regra não excedem os protocolos estabelecidos, como se esse acontecimento (BRAUDEL, 2007) delimitasse, congelasse e padronizasse tempo e espaço. Um presentecomo fragmento de história desprendido do seu passado e do seu futuro, descolado do realconcreto. Especificidades contextuais, diversidade cultural, social e econômica, além das imensas desigualdades regionais e intraurbanas são, assim, abstraídas ou subsumidas nos protocolos generalistas, os quais, embora assertivos nos seus enunciados gerais, não conseguem alcançar a toda a população. Distintas e desiguais realidades, expressas nas cidades brasileiras, exigem adequações das determinações sanitárias, para assim cumprir os seus objetivos.

As estratégias colocadas à população baiana e em especial à soteropolitana para lidar com a pandemia, claramente consideraram um discurso construído do ponto de vista de uma população residente em bairros da cidade com acesso a saneamento, moradias adequadas e transporte individual. Assim, as condições e modos de vida da grande parcela de população vulnerabilizada são abstraídos das políticas de combate à Covid-19 e raramente aparecem nos discursos oficiais ou, quando aparecem,estão associados a contundentes prescrições sem reconhecimento das dificuldades práticas de cumprimento.

Nos contextos estudados, essas especificidades socioeconômicas e culturais não lograram canais de escuta para que fossem colocadas no debate público e atravessassem as estratégias adotadas para frear a pandemia. Observou-se, no entanto, o esforço de lideranças comunitárias no sentido de dar visibilidade pública às dificuldades de cumprimento do distanciamento social pelas populações residentes nos territórios populares. Para isso, estes agentes sociaisse utilizaram de canais de comunicação independente como rádio comunitária e a internet, ou mesmo peças gráficas feitas manualmente e espalhadas pelas comunidades.

Também buscaram formas alternativas e adaptadas aos seus contextos para minimamente assegurar o cumprimento de medidas de higiene e o uso de máscara, além da busca de 
aliados na formação de redes de solidariedade em face da dificuldade de obtenção dos meios de subsistência. Um esforço, apesar de importante, incapaz de lograr resultados efetivos diante da complexidade da situação,quando dissociado de ações planejadas através de políticas públicas construídas de maneira multidisciplinar e participativa.

Os conselhos de políticas públicas podem se constituir como instâncias de mediação entre estado e sociedade civil, dada a capacidade de mobilização de grande parte dos seus integrantes, da diversidade de segmentos envolvidos e da capilaridade territorial. Entre os conselhos vinculados especificamente à pauta urbana no estado da Bahia, por exemplo, nota-se um imenso potencial de formulação e implementação de estratégias regionalizadas para conter a expansão da pandemia.

No município do Salvador, da mesma forma, os meios de sustentação das medidas de distanciamento social ancorados em estratégias construídas, pactuadas e legitimadas pelo Conselho Municipal de Salvador e implementadas com o seu acompanhamento, certamente seriam mais efetivos nos territórios com maiores índices de contaminação. Poderia, por exemplo, fazer a informação chegar à "ponta", criando as narrativas indispensáveis na contraposição às fakenews, que invadiram as redes sociais durante a pandemia (GALHARDI et al, 2020) e aos discursos negacionistas e inverídicos propagados por autoridades públicas, inclusive pelo presidente. Como destaca Sandra Caponi (2020, p.211),

Para evitar a proliferação de discursos negacionistas devem ser ouvidos os argumentos apresentados pelos expertos (e evitados os falsos expertos) não só epidemiologistas, infectologistas, sanitaristas, mas também cientistas sociais, educadores, psicólogos. Acrescentando a eles o saber daqueles que chamaremos aqui de expertos por experiência. Isto é, aqueles que desde seus locais e conhecendo de perto a problemática que cotidianamente vivenciam podem auxiliar-nos a criar redes de ajuda, cuidado e informação.

Mais do que fazer as informações chegarem aos territórios onde a Covid-19 encontra terreno fértil é acionar mecanismos de pressão ancorados em dados e informações sobre as especificidades dos contextos onde a doença se instala e se propaga com maior facilidade diante de determinadas condições de vulnerabilidade. Exercer a chamada estratégia de enumeração (MCFARLANE, 2006), que consiste na apuração e compilação de dados e informações locais que demonstrem aos governantes alternativas às políticas encaminhadas na lógica hegemônica de deslegitimação, invisibilização e silenciamento desses territórios.

Tal estratégia ganharia efetividade em esforço combinado de articulação dos conselhos de política urbana com os conselhos de saúde, envolvendo inclusive os agentes comunitários de saúde, agentes estratégicos nas políticas de prevenção à Covid-19.

Esse evidente apelo a uma política urbana orientada para a redução das desigualdades socioespaciais e enfrentamento da problemática habitacional do país, trazido pela pandemia, não 
logrou reconhecimento das instâncias governamentais na Bahia e em Salvador. Prova disso são as ações de reintegração de posse em curso em Zonas Especiais de Interesse Social, a exemplo da ZEIS do Tororó (IBDU, 2020), alterações de poligonais de ZEIS, como ocorrido nas ilhas de Salvador (SALVADOR, 2020) e desapropriações durante a crise sanitária.

A indispensável abordagem articulada de política de saúde e política urbana na pandemia da Covid-19 não parece ter reconhecimento dos gestores à frente das pastas no governo do estado da Bahia e da Prefeitura Municipal do Salvador e, como evidencia a pesquisa realizada, não ensejou uma postura crítica e contestatória por parte dos conselhos, como será visto a seguir.

\section{FORMAÇÕES E TRAJETÓRIAS DO CONSELHO ESTADUAL DAS CIDADES DA BAHIA E DO CONSELHO MUNICIPAL DE SALVADORE ENVOLVIMENTO NAS POLÍTICAS DE PREVENÇÃO E COMBATE À COVID-19}

A Constituição Federal/1988 foi fruto de intensa mobilização de políticos e da sociedade, numa operação que durou três anos, contados a partir da convocação da Assembleia Nacional Constituinte (ANC) em 1985. Entre os resultados da pressão da sociedade civil na ANC, estabelece-se na Carta Constitucional um novo desenho político-institucional, pela garantia de espaços públicos de participação, que compreendem, entre outros, os Conselhos e as Conferências de políticas públicas. $\mathrm{Na}$ visão de Dagnino (2002), a sociedade civil desempenhou papel determinante no processo de transição democrática brasileiro, na medida em que reuniu diferentes segmentos (não sem conflitos e contradições), mas conseguiu a unificação em torno da luta contra o regime autoritário.

Com o aprofundamento democrático, houve um aumento significativo do número de entidades associativas, assim como uma mudança qualitativa, pelo surgimento de entidades voltadas para direitos humanos, meio ambiente e outras, incorporando demandas relativas a direitos (AVRITZER, 2012). Entretanto, as políticas neoliberais dos anos 1990 tiveram como consequência o agravamento das desigualdades sociais e econômicas que repercutiram, também, sobre a capacidade de mobilização e organização política da sociedade civil, quando os movimentos sociais perdem terreno para as organizações não governamentais (ONGs), implicando em certas dificuldades no ritmo da democratização (DAGNINO, 2002).

De acordo com Almeida, Cayres e Tatagiba (2015, p. 256), a década de 2000 é a época de expansão no nível federal e consolidação dos conselhos "como parte da arquitetura institucional do Estado brasileiro". Consagrados na Lei 10.257/2001, os Conselhos das Cidades se revestem de um imenso potencial de luta por direitos na cidade e pelo controle social de processos e projetos urbanos. Com limitações de operacionalidade frente às realidades diversas das cidades brasileiras, estão na 
base de experimentação da política urbana nas cidades. Sua legitimidade 0 credencia enquanto orientador de processos de alargamento da democracia no Brasil ao instituir nas cidades o princípio da participação social em situações em que um projeto de cidade e de sociedade esteja em discussão.

4.1 Conselho Estadual das Cidades da Bahia: um potencial desperdiçado

O Conselho Estadual das Cidades da Bahia - ConCidades-BA, foi criado pela Lei $n^{0}$ 10.704, em 12 de novembro de 2007, durante o primeiro governo petista do Estado, como órgão colegiado de natureza permanente, de caráter deliberativo, consultivo e fiscalizador, da estrutura da Secretaria Estadual de Desenvolvimento Urbano - Sedur. Já no primeiro parágrafo da lei de criação é explicitado que se articula ao Ministério das Cidades, por meio do Conselho Nacional das Cidades, numa clara vinculação às diretrizes da política urbana nacional.

É composto por representantes do poder público e da sociedade civil, sendo que a representação da sociedade civil é proporcionalmente superior, considerando-se todos os segmentos, totalizando 61 componentes ${ }^{4}$. A presidência do ConCidades é exercida pelo Secretário Estadual de Desenvolvimento Urbano e, com exceção dos representantes do poder público estadual, incluindo dois representantes da Assembleia Legislativa Estadual, indicados pelo secretário da Sedur e pelo Presidente da Assembleia, respectivamente, todos os representantes dos demais segmentos são eleitos na Conferência Estadual das Cidades, entre os delegados presentes de seus respectivos segmentos, com mandado coincidente com a periodicidade das Conferências Estaduais. Para o seu funcionamento, o ConCidades-BA conta com o plenário, a presidência, a secretaria executiva e Câmaras Técnicas (Habitação, Saneamento Básico, Mobilidade Urbana e Planejamento e Gestão Territorial Urbana, com funcionamento e atribuições de assessoria ao ConCidades definidos no Regimento Interno, sendo prevista a criação de grupos de trabalho (GT) para temas específicos, através de resoluções aprovadas em reuniões plenárias.

Ainda conforme o Regimento, embora seja competência do Presidente do Conselho a convocação de reuniões plenárias (Art. 19, Inciso I), as reuniões extraordinárias poderão ser convocadas por $20 \%$ dos membros do ConCidades, com representação mínima de 4 segmentos (Art. 11). Ao plenário cabe, além do poder deliberativo mediante resolução aprovada pela maioria dos seus membros titulares, constituir e aprovar a composição de grupos de trabalho, solicitar às Câmaras Técnicas pareceres sobre matérias específicas e solicitar estudos ou pareceres técnicos especializados quando do seu interesse.

Embora bem estruturado e funcionando com regularidade, com reuniões bimensais, exceto em 2020 a partir da crise sanitária, é possível identificar que o processo de participação ou a 
relação da sociedade civil com o Estado não é linear e apresenta dificuldades. Reportam-se, sobretudo, a diferentes compreensões dos papéis atribuídos, conhecimento do aparato estatal, capacidade orgânica, formações políticas e culturais. Dagnino enfatiza a dimensão cultural dos processos de consolidação democrática no país, considerando que é "nesse campo que as contradições e a fragmentação que caracterizam esse processo se mostram mais evidentes." (DAGNINO, 2002, p. 280).

Segundo a autora, a interação entre sociedade civil e Estado é sempre tensa e permeada pelo conflito, em maior ou menor intensidade conforme o grau de identificação ou estranhamento entre os projetos políticos. Cabe lembrar que as gestões do Partido dos Trabalhadores (PT), tanto a nível federal como dos estados e municípios, introduziram algumas práticas, como orçamento participativo, conselhos e Conferências de políticas públicas que materializaram a participação da população conforme preconizado na Constituição Federal, que se tornou uma espécie de marca das administrações petistas, conseguindo, dessa forma, estabelecer um diálogo, em certa medida e durante certo tempo, mais próximo e confiante com os movimentos sociais e entidades, porém contraditório e ambíguo (VIVEIROS, 2018).

A despeito do alinhamento político, cabe uma observação em relação a uma prática da cultura política brasileira, que não foi rompida com as administrações progressistas, que se refere à verticalidade das relações entre Estado e Sociedade. Não obstante a experiência adquirida nos 13 anos de atuação desse colegiado e de certo grau de amadurecimento político de seus integrantes, ainda prevalecem as relações hierárquicas, com relativa assimetria em favor de técnicos e gestores estaduais. As frequentes demandas por "capacitação" pelos conselheiros, registradas nas atas de reuniões, evidenciam o interesse em processos formativos para o pleno exercício das atribuições que Ihe são conferidas, destacadamente a capacidade de formulação de políticas e de análise e compreensão do orçamento público.

4.2 Conselho Municipal de Salvador: anulação da dimensão do político e legitimação das ações do governo

0 Conselho Municipal de Salvador (CMS) foi criado pela Lei $n^{0} 7.400 / 2008$, alterada pela Lei 9.069 de 30 de junho de 2016, que dispõe sobre o Plano Diretor de Desenvolvimento Urbano de Salvador (PDDU - Salvador), no capítulo que trata do Processo de Desenvolvimento Urbano do Município, onde são definidos os instrumentos de participação no planejamento municipal. 0 Art. 354 define o Conselho como órgão permanente, de caráter consultivo, composto por representantes do poder público e da sociedade civil. 
Conquanto instituído no interior do PDDU, sua centralidade na formulação e implementação da política urbana é dissipada no conjunto dos instrumentos de participação, não trazendo desde seu título sua vinculação como órgão gestor da política urbana municipal (como explicitado com a Conferência Municipal da Política Urbana, que também integra o conjunto de instrumentos do artigo 353), podendo referir-se a qualquer categoria no conjunto de conselhos existentes, como "outros conselhos, comissões e fóruns legalmente instituídos" (inciso 3 do mesmo artigo) ou ainda o Sistema Municipal de Ouvidorias (parágrafo único do art. 353), sem vinculação a um sistema ou legislação nacional (TATAGIBA, 2002, p. 49), no caso, o Estatuto da Cidade, que regulamenta os capítulos constitucionais da Política Urbana, sem embargo se afirme no parágrafo único do artigo 354 que o mesmo "é parte integrante dos sistemas nacional e estadual de desenvolvimento urbano" (SALVADOR, 2016).

Não obstante instituído como "órgão permanente", o caráter consultivo lhe dá o status de simples comissão externa com finalidade opinativa ou de aconselhamento, sem força para interferir na elaboração da política urbana, o que contradiz a condição de órgão colegiado, que pressupõe a igualdade de poderes entre os pares que compõem tal estrutura, reafirmando, assim, a assimetria entre Estado e sociedade anteriormente mencionada.Os seus objetivos, definidos nos incisos de I a VI do referido artigo 354, Ihe atribuem um papel instrumental ou legitimador, característica dos modelos de gestão tecnocráticos, inadvertidamente explicitado no inciso III: "propiciar respaldo político às decisões e diretrizes do planejamento e gestão municipal" (SALVADOR, 2016).

Apesar de criado originalmente no PDDU de 2008, o Conselho Municipal de Salvador só teve sua composição definida 10 anos depois, pelo Decreto Municipal $n^{0}$. 29.563.859/2018, alterado pelo Decreto Municipal $n^{\circ} 30.859$ de 14/03/2019. Posteriormente foi aprovado o regimento pelo Decreto 31.796 de 20 de novembro de 2019, no qual estão definidas, suas atribuições, as do presidente e as dos conselheiros.

Não obstante pareça estar funcionado regularmente, no que se deduz pela agenda de reuniões disponibilizada no site da Secretaria Municipal de Desenvolvimento e Urbanismo, apenas foram localizadas cinco atas de reunião, sendo duas de 2018 e três de 2019. Também se identificou um ato do Conselho, a Resolução $n^{0}$ 01, de 03 de maio de 2019, que dispõe sobre os critérios de priorização dos beneficiários do Programa Minha Casa, Minha Vida. Em 2020 não foram realizadas reuniões, mesmo virtuais, embora parte das atividades da administração estivesse sendo desenvolvida de forma remota, durante o período mais agudo da pandemia. 


\subsection{Os Conselhos na Pandemia da Covid-19}

Em ambos os conselhos analisados, sem desconsiderar suas diferenças intrínsecas de constituição (deliberativo/consultivo; modelo democrático-participativo/modelo tecnocrático, entre outras) dois pontos se destacam: i) a incapacidade propositiva, seja por dificuldades de compreensão da estrutura do Estado e da política pública, seja pelas contenções impostas pelo modelo de gestão que limita a atuação do conselho ao meramente legitimador; ii) a histórica assimetria das relações entre estado e sociedade, que em ambas as situações não parecem ser percebidas ou contestadas.

A partir deste comentário, tendo em conta a situação atual da crise pandêmica que alterou a rotina das cidades em quase todas as partes do mundo, e que ressaltou, com capacidade telescópica, as desigualdades existentes no mundo capitalista, notadamente nos países não hegemônicos, surpreende que o tema não tenha despertado o interessee ensejado a mobilização e 0 acionamento de mecanismos de pressão dos Conselhos estudados, considerando as desigualdadessociais e territoriais, especialmente em Salvador,diante do alto índice de contaminação e mortes diariamente anunciados nas mídias.

No Conselho Municipal de Salvador, as atividades foram simplesmente suspensas, sem nenhuma notícia de que tenha havido qualquer tipo de mobilização em sentido contrário por parte dos conselheiros. Havia reunião agendada, ainda no formato presencial, para 18 de março de 2020, que seria a primeira do ano, porém poucos dias antes foram proibidas reuniões presenciais, e assim houve 0 cancelamento sem remarcação de nova data. O Conselho se manteve desarticulado e sem atuação na orientação das políticas públicas de prevenção e combate ao coronavírus, tendo participado, entretanto, de reunião para a discussão do Plano Salvador 500, um plano de ação em desenvolvimento pela Prefeitura Municipal do Salvador.

Por seu turno, no ConCidades-BA, embora tenham sido promovidas reuniões remotas em 2020, as atas divulgadas não revelam qualquer iniciativa de pautar a política urbana como dimensão básica e estratégica para conter a pandemia da Covid-19. Na primeira, ocorrida em 22 de julho de 2020, no formato remoto, o tema da pandemia da Covid-19 não foi tratado como pauta principal, e até 0 momento de elaboração do presente artigo nada havia sido discutido nas câmaras técnicas, sendo a situação da crise sanitária tratada apenas comoempecilho para a continuidade das atividades programadas para o Conselho devido ao impeditivo dos encontros presenciais.

A segunda reunião, realizada em 31 de agosto de 2020, também em formato remoto,reitera a inércia do Conselho para influenciar nas políticas públicas de enfrentamento à pandemia, embora registre discussão ocorrida na Câmara Técnica de Planejamento e Gestão Territorial Urbana - CT/PGTU sobre projeto de cooperação técnica entre a Sedur e a Universidade 
Federal da Bahia - UFBA intitulado de "Projeto de Desenvolvimento Urbano Contra o Covid-19", voltado ao mapeamento dos problemas relativos ao desenvolvimento urbano para o controle da pandemia. Foram feitos também relatos sobre a propagação do Covid-19 nas cidades, com destaque para os territórios de residência dos Conselheiros e discutida a participação dos conselheiros no levantamento de dados.A terceira reunião ocorreu no dia 16 de dezembro e ainda não teve a sua ata aprovada, o que está previsto para a próxima reunião, como de praxe, sendo este requisito para a sua divulgação.

\section{CONSIDERAÇÕES FINAIS}

Embora seja certa a tese da ampliação de espaços de participação e controle social na gestão das políticas públicas, não tão certa é a capacidade de efetivamente influenciar nessas políticas, acompanhar a implementação e ir além dessa tarefa no exercício ampliado da política no sentido de interferir nos processos decisórios maiores, como, por exemplo, na elaboração das políticas públicas, dos planos e do orçamento público.

Nos casos analisados, as dificuldades de compreensão mais ampla da agenda da reforma urbana marcam a história dos dois conselhos. No contexto da pandemia da Covid-19, essa constatação apenas fica mais evidente, pelo fato de a pandemia esviscerar as contradições do modelo de urbanização das cidades brasileiras e não ser discutida nesses termos pelos colegiados aqui tratados.

No Concidades-BA a discussão sobre temas centrais da política urbana, como o princípio da função social da cidade e da propriedade, espaço público, gestão democrática das cidades, regiões metropolitanas etc. raramente acontece. Em alguns momentos são observadas referências à política estadual de desenvolvimento urbano da Bahia nos debates, mas o tema não logrou força suficiente para se afirmar na agenda pública. No Conselho Municipal de Salvador, ao que se observa, não há mesmo uma compreensão clara por parte dos integrantes do seu papel e responsabilidade na política urbana.

Cabe ainda destacar o reduzido exercício da prerrogativa de deliberação do ConcidadesBA, constatada em dois aspectos. 0 primeiro diz respeito ao pouco aprofundamento dos debates em torno de temas complexos na plenária do Conselho e mesmo nas Câmaras Técnicas. O segundo refere-se ao pouco tempo de discussão reservado a esses mesmos temas e ao seu amadurecimento. Mesmo havendo votação sobre temas específicos, o tratamento superficial de assuntos complexos coloca em questão o conhecimento efetivo sobre o objeto da decisão.

A pesquisa confirma a ausência de percepção, por parte dos conselheiros, do potencial de pressionar o Estado para fazer avançara política urbana, em um contexto de flagrante evidenciação 
das contradições do modelo de desenvolvimento urbano hegemônico. O enfoque setorial na discussão dos temas da agenda da política urbana, observado durante todo o período de existência do ConCidades-BA e também do Conselho Municipal de Salvador,pode explicar dificuldades no entendimento da estreita relação da política urbana com a política de saúde, em condições de emergência sanitária.

Razões podem ser encontradas na postura pouco ativa no sentido de pautar temas além daqueles próprios da agenda governamentale na história de reduzidos contrapontose conflitos frente às proposições apresentadas pelo governo, mesmo no Concidades-BA, com a sua "maturidade" e presença de membros com larga experiência de militância política e de participação nesses órgãos. No ConCidades-BA são raras as discussões sobre conjuntura e assuntos que extrapolam o âmbito das políticas setoriais da pasta da Sedur. No Conselho Municipal de Salvador as atas não registram os debates.

As instâncias governamentais, por outro lado, não foram capazes de incorporar nas políticas de combate à Covid-19, a imensa capacidade de articulação desses órgãos colegiados na implementação das ações que atendam às urgências do momento, incorporando olhares e narrativas mais próximas e contextualizadas. Também não aparece nos informes dos gestores públicos, a atuação dos órgãos aos quais os conselhos estão vinculados, sobre os respectivos engajamentos nas ações de contenção e combate à pandemia, o que pode revelar o não envolvimento direto, o que é mais crítico, ou o entendimento de não ser importante partilhar esse esforço com o Conselho.

\section{REFERÊNCIAS}

ALMEIDA, Carla; CAYRES, Domitila Costa; TATAGIBA, Luciana. Balanço dos Estudos sobre os Conselhos de Políticas Públicas na Última Década. Disponível em: https://www.scielo.br/pdf//n/n94/0102-6445-In-94-00255.pdf . Acesso em: 15 dez.2020.

AVRITZER, L.; PEREIRA, M. DE L. D. Democracia, participação e instituições híbridas. Teoria \& Sociedade, Belo Horizonte, p. 1641, 2005.

AVRITZER, L. Participação social no Brasil. Relatório de Pesquisa. Belo Horizonte, UFMG, 2009.

AVRITZER, Leonardo. Sociedade civil e Estado no Brasil: da autonomia à interdependência política. Opinião Pública, Campinas, v. 18, n. 2, nov. 2012, p. 383-398.

ALMEIDA, C; TATAGIBA, L. Os conselhos gestores sob o crivo da política: balanços e perspectivas.

Serv. Soc. Soc., São Paulo, n. 109, p. 68-92, jan./mar. 2012. 
BEHRING. Elaine Rosseti. Brasil em contra-reforma: desestruturação do Estado e perda de direitos. São Paulo: Cortez, 2003.

BOBBIO, N. Democracia representativa e democracia direta. In: 0 futuro da democracia. São Paulo: Paz e Terra, 2000.

BORÓN, Atílio. A sociedade civil depois do dilúvio neoliberal. In: SÁDER, Emir; GENTILI, Pablo (orgs.). Pós-neoliberalismo. As Políticas Sociais e o Estado Democrático. Rio de Janeiro: Paz e Terra, 1995.

BRAUDEL, Fernand. História e Ciências Sociais: a longa duração. In: BRAUDEL, Fernand. Escritos sobre a História. Traduzido por J. Guinburg e Tereza Cristina Silveira da Mota. São Paulo:

Perspectiva, 2007.

CAPONI, Sandra. Covid-19 no Brasil: entre o negacionismo e a razão neoliberal. Estudos Avançados, n. 34, 2020. Disponível em: https://www.scielo.br/scielo.php?script=sci_arttext\&pid=S0103$40142020000200209 \&$ tlng=pt. Acesso em: 14 dez. 2020.

CHESNAIS, François. Crise de sobreacumulação global iniciando uma crise de civilização. In. RIBEIRO, Luiz Cesar de Queiroz. As metrópoles e o capitalismo financeirizado, Rio de Janeiro: Letra Capital : Observatório das Metrópoles, 2020, p. 63-87.

DAGNINO, E. (org.). Sociedade civil e espaços públicos no Brasil. São Paulo: Paz e Terra, 2002, $364 \mathrm{p}$.

DAGNINO, E. ¿Sociedade civil, participação e cidadania: de que estamos falando? In: Políticas de Ciudadanía y Sociedad Civil en tiempos de globalización. Caracas: FACES, Universidad Central de Venezuela Editorial, 2004.

DOWBOR, Ladislau. 0 capitalismo se desloca: novas arquiteturas sociais. São Paulo: Edições Sesc São Paulo, 2020.

FERNANDES, Ana. Decifra-me ou te devoro: Urbanismo corporativo, cidade-fragmento e dilemas da prática do Urbanismo no Brasil. In: GONZALES, Suely; FRANCISCONI, Jorge Guilherme; PAVIANI, Aldo. Planejamento e Urbanismo na atualidade brasileira:objeto teoria prática. São Paulo, Rio de Janeiro: Livre Expressão, 2013.

GALHARDI, Cláudia Pereira; FREIRE, Neyson Pinheiro; MINAYO, Maria Cecília de Souza; FAGUNDES, Maria Clara Marques. Fato ou Fake? Uma análise da desinformação frente à pandemia da Covid-19 no Brasil. Revista Ciência \& Saúde Coletiva, n.25

https://www.scielosp.org/article/csc/2020.v25suppl2/4201-4210/. Acesso em: 12 Dez. 2020.

GALVÃO, Andréia. Neoliberalismo e reforma trabalhista no Brasil. Rio de Janeiro: Revan, 2007.

GAUDIN, J. P.; PEREIRA, M. L. D. As políticas públicas locais e os processos de "hibridação" no Brasil e na França. Anais... 29. Encontro Associação Nacional de Pós-Graduação e Pesquisa em Ciências Sociais (Anpocs). 2005. Disponível em: https://anpocs.com/index.php/papers-29-encontro/gt-25/gt0117/3630-gaudin-pereira-as-politicas/file. Acesso em 10 out. 2020. 
GEOCOMBATE Covid 19/BA. Nota Técnica n. 5. Análise da Interiorização da COVID-19 na Bahia, 24 de julho de 2020. Disponível em:

https://drive.google.com/file/d/1geBU42VS7RGEXpx566EBsllepc3InWIJ/view. Acesso em: 10 out. 2020.

GOHN, M. G. Conselhos gestores e participação sociopolítica. 2. ed. São Paulo: Cortez, 2003.

GROSSBERG, Lawrence. Lutando com anjos: os estudos culturais em tempos sombrios. MATRIzes, v.9, n. 2, jul./dez. 2015, São Paulo, p. 13-46.

HARVEY, David. O neoliberalismo: história e implicações. São Paulo: Loyola, 2008.

IBDU. Nota Técnica sobre o Regime Jurídico das Zonas Especiais de Interesse Social. Disponível em: http://bit.ly/3h3Arvg. Acesso em: 19 Dez. 2020.

MCFARLANE, Colin. Transnational development networks: bringing development and postcolonial approaches into dialogue. The geographical journal, n.172, v.1, 2006. p. 35-49.

PEREIRA, G. C. et. al. A pandemia da COVID-19 em uma cidade pobre e periférica: desigualdades e vulnerabilidades socioespaciais, governança e políticas de enfrentamento em Salvador e em sua Região Metropolitana. In. RIBEIRO, Luiz Cesar de Queiroz. As metrópoles e a COVID-19: dossiê nacional.(org). Rio de Janeiro: Observatório das Metrópoles, 2020, p. 440-477. Disponível em: https://drive.google.com/drive/folders/1-s_FlkfbUovR6KyWUjOljQF5DaQ_7vmU. Acesso em: 10 dez. 2020.

PONTUAL, Pedro. Desafios à construção da democracia participativa no Brasil: a prática dos conselhos de gestão das políticas públicas. Revista de Debates do Centro de Assessoria e Estudos Urbanos. v. 1, n. 1, p. 160-185, dez. 2008. Disponível em: https://polis.org.br/wpcontent/uploads/2020/03/pontual.pdf. Acesso em: 15 nov. 2020.

RIBEIRO, Luiz Cesar de Queiroz. Inflexão ultraliberal e a financeirização da ordem urbana brasileira: explorando algumas hipóteses. In. RIBEIRO, Luiz Cesar de Queiroz. As metrópoles e o capitalismo financeirizado, Rio de Janeiro: Letra Capital: Observatório das Metrópoles, 2020, p. 371-418. Disponível em: https://www.observatoriodasmetropoles.net.br/as-metropoles-e-o-direito-a-cidade-nainflexao-ultraliberal-da-ordem-urbana-brasileira-texto-para-discussao. Acesso em: 15 nov. 2020.

SANTOS JÚNIOR, O. A.; RIBEIRO, L. C. Q. \& AZEVEDO, S. Democracia e gestão local: a experiência dos conselhos municipais no Brasil. In : (orgs.). Governança democrática e poder local. A experiência dos conselhos municipais no Brasil. Rio de Janeiro: Revan, 2004

SANTOS JUNIOR, O. A. dos; DINIZ, T. M. R. de G.; SAULE JUNIOR, N. Dossiê do Desmonte da Política Urbana Federal nos Governos Temer e Bolsonaro e Seus Impactos Sobre as Cidades: Violações de Direitos Humanos e os Riscos de Construção de Cidades Intolerantes, Excludentes, Injustas e Antidemocráticas. Rio de Janeiro: IPPUR/UFRJ, 2020. Disponível em: https://www.observatoriodasmetropoles.net.br/wp-content/uploads/2020/02/Dossi\%C3\%AA-FNRU2020-Final.pdf. Acesso em: 12 nov. 2020.

SÁDER Emir; GENTILI, Pablo (orgs.). Pós-neoliberalismo. As Políticas Sociais e o Estado Democrático. Rio de Janeiro: Paz e Terra, 1995. 
SALVADOR. Secretaria de Desenvolvimento e Urbanismo. Conselho Municipal de Salvador. Disponível em: http://www.sucom.ba.gov.br/programas/conselho-municipal-de-salvador. Acesso em: 18 nov. 2020.

SALVADOR. Lei Complementar nº 074/2020. Institui o Programa de Regularização Fundiária Urbana e estabelece normas e procedimentos aplicáveis ao Procedimento Administrativo de Regularização Fundiária Urbana. Diário Oficial do Município, Salvador, 2020.Disponível em:

http://www.sucom.ba.gov.br/wp-content/uploads/2020/03/lei_complementar_074_2020.pdf. Acesso em: 10 de Dez. 2020.

SALVADOR. Lei n $9.069,30$ de junho de 2016. Dispõe sobre o Plano Diretor de Desenvolvimento Urbano do Município de Salvador - PDDU 2016 e dá outras providências. Diário Oficial do Município, Salvador, 2016.Disponível em:https://leismunicipais.com.br/plano-diretor-salvador-ba.Acesso em: jul.2016.

SALVADOR. Lei municipal $n^{0} 7.400$, de 2008. Dispõe sobre o Plano Diretor de Desenvolvimento Urbano do Município do Salvador 2008. Disponível em: http://www.sedham.salvador.ba.gov.br.Diário Oficial do Município, Salvador, 2008. Acesso em: 10 jun. 2009.

TATAGIBA, L. Os Conselhos e a construção da democracia no Brasil: um rápido balanço de duas décadas de participação conselhista. In. RUBIM, Albino; FERNANDES, Taiane; Rubim, luri. (orgs). Políticas culturais, democracia e conselhos de cultura. Salvador: Edufba, 2010, p. 27-50. Disponivel em:

file://C:/Users/aparecidant/Downloads/textos\%20artigo\%20conselho_politica\%20urbana\%20BR/coleca 0\%20cult_8_RI.pdf. Acesso em: 18 nov. 2020.

TATAGIBA, L. Os Conselhos gestores e a democratização das políticas públicas no Brasil. In: DAGNINO, E. (org.). Sociedade civil e espaços públicos no Brasil. São Paulo: Paz e Terra, 2002, $364 \mathrm{p}$.

TEIXEIRA, Ana Claudia. Os sentidos da democracia e da participação. São Paulo: Instituto Pólis, 2005.

TÓTORA, S.; CHAIA, V. Conselhos municipais e a institucionalização da participação política: a Região Metropolitana de São Paulo. In: SANTOS JÚNIOR, O. A. DOS, RIBEIRO, L. C. Q.; AZEVEDO, S. (org.). Governança democrática e poder local: a experiência dos conselhos municipais no Brasil. Rio de Janeiro: Revan/Fase, 2004.

VIVEIROS, L.Práxis de Política Urbana no Brasil: Movimentos e Articulações Nacionais e Internacionais na Construção do Direito à Cidade. 407 f., 2018. Tese (Doutorado). Programa de Pós-Graduação em Arquitetura e Urbanismo, Universidade Federal da Bahia, Salvador, 2018.

VIVEIROS; L.; LIMA, A. N. V.; SOUZA, M. J.A. O Direito nas trincheiras da cidade: urbanismo corporativo e práticas contra-hegemônicas. Revista Práxis. 2020, p. 612-644.

\section{Notas}

1 O Decreto $n^{0} .5 .031$, de 02 de abril de 2004, dispôs sobre a composição, estruturação, competências e funcionamento do ConCidades, tendo sido substituído pelo de Decreto n. 5.790, de 26 de maio de 2006. 
2 Pode-se destacar o Sistema Nacional de Habitação de Interesse Social (SNHIS), a Política Nacional de Habitação e Interesse Social e o Fundo Nacional de Habitação de Interesse Social (FNHIS) (2005); a Lei Nacional de Saneamento Básico (2007); a Política Nacional de Mobilidade Urbana (2012).

${ }^{3}$ Registra-se ainda o CONEA (Conselho Nacional de Segurança Alimentar e Nutricional), a Comissão Nacional para Erradicação do Trabalho Escravo, o Conselho Nacional de Combate à Discriminação e Promoção dos Direitos de LGBT.

${ }^{4}$ Dentre esses, os movimentos sociais e populares são o segmento de maior representação, seguindo a mesma orientação do Conselho Nacional das Cidades por uma gestão mais democrática. Sua composição proporcional por segmentos é definida na Lei de criação, da seguinte forma: $42,3 \%$ do Poder Público, 26,7\% do movimento social e popular, 9,9\% dos trabalhadores, $9,9 \%$ dos empresários, $7 \%$ das entidades profissionais de ensino e pesquisa e 4,2\% de organizações nãogovernamentais. 